\title{
Descripción de frutales nativos de la familia Ericaceae en el altiplano de Pasto, Colombia
}

\author{
Description of native fruit trees of Ericaceae family \\ in the highlands of Pasto, Colombia
}

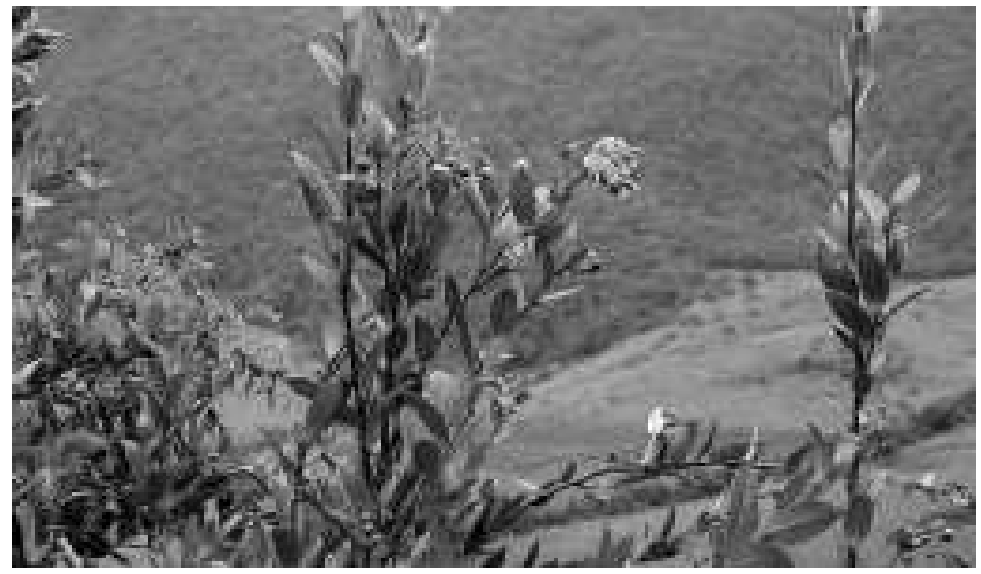

TULIO CÉSAR LAGOS-BURBANO1,2

HÉCTOR ORDÓNEEZ-JURADO'

HERNANDO CRIOLLO-ESCOBAR ${ }^{1}$

SOFÍA BURBANO'

YOHANA MARTINEZ

\section{RESUMEN}

Una de las fuentes alimenticias de los habitantes de la región andina del departamento de Nariño (Colombia) son los frutales nativos, que han sido utilizados por todas las culturas desde tiempos inmemoriales; de ellos, solo algunos han sido domesticados, la mayoría están en estado silvestre; existen pocas investigaciones sobre su potencial nutritivo, industrial, bioquímico, medicinal y ornamental, y sus hábitats están amenazados debido a la deforestación, la ampliación de la frontera agrícola y la siembra de cultivos ilícitos. El objetivo del presente estudio fue identificar frutales nativos de la familia Ericaceae y describir in situ sus principales características vegetativas y reproductivas, su distribución ecológica y manejo por las comunidades locales. Se identificaron Ias especies Thibaudia floribunda, Disterigma acuminatum, Gaultheria cordifolia, G. foliosa, G. insipida, Cavendishia tubiflora, C. bracteata, Macleania rupestris y Vaccinium floribundum; la más representativa fue $D$. acuminatum, y la de menos frecuencia fue $V$. floribundum. En la mayoría de estas especies, el fruto es utilizado en dulces y mermeladas; Ios frutos de V. floribundum y $M$. rupestris se comercializan en Pasto y municipios aledaños.

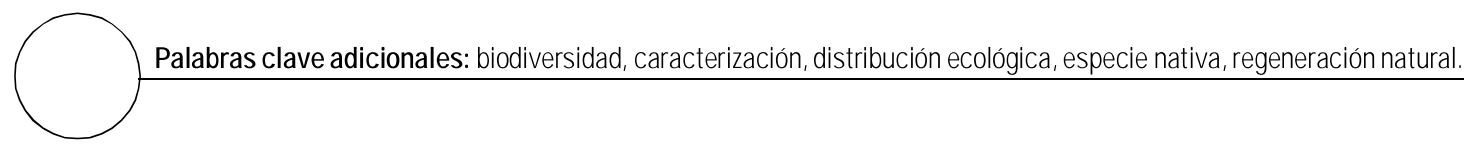

\footnotetext{
1 Facultad de Ciencias Agrícolas, Universidad de Nariño, Pasto (Colombia).

2 Autor para correspondencia.tclagosb@udenar.edu.co
} 


\section{ABSTRACT}

One food source of the inhabitants of the Andean region in Nariño (Colombia) is native fruits, which have been used by all cultures since their origin. Although a few of these plants have been domesticated, many are in the wild. There are a few studies on their nutritional, industrial, biochemical, medicinal, and ornamental potential. Their habitats are threatened by deforestation, agricultural expansion and the cultivation of illicit crops. The aim of this study was to identify native fruits of the family Ericaceae, describing in situ the main vegetative and reproductive features, ecological distribution and management by local communities. Species Thibaudia floribunda, Disterigma acuminatum, Gaultheria cordifolia, G. foliosa, G. insipidus, Cavendishia tubiflora, C. bracteata, Macleania rupestris, Vaccinium floribundum were identified. The most representative was $D$. acuminatum. The least common was $V$. floribundum. In most species, the fruits are used in jams and marmalades. The fruits of $V$. floribundum and $M$. rupestris are sold in Pasto and surrounding municipalities.

Additional key words: biodiversity, characterization, ecological distribution, native species, natural regeneration.

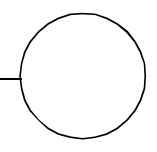

Fecha de recepción: $\quad$ 17-03-2010

Aprobado para publicación: 02-06-2010

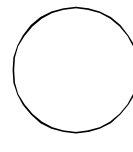

Vavilov (1960) indica que la región andina es uno de los mayores centros de domesticación de plantas del mundo y que fue escenario de civilizaciones que desarrollaron una agricultura autóctona con la domesticación de gran número de especies de plantas nativas, que fueron su base al imenticia durante siglos, hasta la llegada de los españoles, periodo en que las especies nativas fueron reemplazadas por especies exóticas traídas de Europa (Sanjinés et al., 2006). Hoy es posible encontrar variedad de frutos nativos de particular importancia para campesinos y pequeños agricultores, debido a que pueden ser cultivados fácilmente alrededor de sus casas, chacras y huertas, y constituyen un recurso importante como alimento y como fuente de pequeños ingresos por su venta (National Research Council, 1989); muchos de estos frutos andinos están recobrando su valor, dado el gran potencial comercial que presentan por su excelente calidad para el consumo directo (Vásquez y Coímbra, 2002; Sanjinés et al., 2006); algunos contienen fitoquímicos que pueden reducir el riesgo de enfermedades crónicas (Pennington y Fisher, 2009); en particular, bajo la denominación de frutos andinos exóticos, su demanda se ha incrementado en Norte América, Europa y Japón, donde son comercializados en tiendas exclusivas en las que los consumidores pagan costosos
INTRODUCCIÓN

precios por fruta fresca traída del otro lado del mundo.

Por su importancia como frutal, la familia Ericaceae es uno de los componentes florísticos más sobresalientes del neotrópico, comunes en las zonas montañosas del noroccidente de Suramérica, especialmente en la vertiente pacífica de los Andes (Luteyn y Sylva, 1999; Salinas y Betancur, 2005); en Ios bosques de niebla se destacan por su función ecológica (Luteyn y Pedraza-Peñaloza, 2008). En Colombia, el potencial de estos frutos lo determina la variabilidad, dado que la zona andina corresponde al área de diversidad primaria de estos frutales, y que existen nichos ecológicos apropiados para el cultivo, así como la amplia aceptación para el consumo nacional y la exportación (Ligarreto et al., 2005). En el departamento de Nariño, la familia Ericaceae es una de las más importantes en los bosques andinos, principalmente en los bosques montanos y en el piedemonte de los páramos, donde juega un importante papel ecológico, como regulador hídrico, y es fuente alimenticia

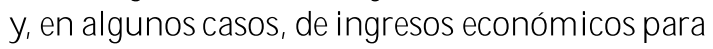
los habitantes de la región, por la venta de los frutos. 
Las ericáceas tienen 4.500 especies a nivel mundial y alrededor de 900 en América tropical (Smith et al., 2004); estas especies presentan hábitos variados, desde arbustos epífitos o hemiepífitos hasta litófitos. Salinas y Betancur (2005) indican que presentan una alta diversidad de géneros y especies, entre ellas Rhododendron (con más de 1.000 especies), Erica (con cerca de 860 especies), Vaccinium (con cerca de 450 especies), Cavendishia (con cerca de 130 especies) y Gaultheria (con cerca de 115 especies); por otra parte, tienen amplia distribución geográfica y abarcan todos los continentes, a excepción de la Antártida. Los principales centros de diversidad se encuentran en las regiones montañosas del neotrópico y de Papúa, Nueva Guinea (Kron et al., 2002); en el neotrópico, la familia está representada por 46 géneros y cerca de 800 especies, es decir, por el $70 \%$ de sus géneros y el 95\% de sus especies, aproximadamente (Luteyn, 2002).

Maecha (1997) menciona que las ericáceas presentan hojas simples, alternas, helicoidales, sin estípulas, sin exudado, curvinervias o penninervias, pequeñas o medianas, con brácteas o cogollos rojizos, en algunas especies cartáceas. Muchas son alimento de la avifauna, y algunas, del hombre. El mismo Maecha sostiene que Colombia es el país más diverso de América en ericáceas, con 22 géneros y cerca de 270 especies.

Para describir las especies frutales nativas pertenecientes a la familia Ericaceae, se consideraron características visibles o fenotípicas. Según Hidalgo (2003), dentro de la variabilidad fenotípica se encuentran las características botánicas-taxonómicas, las morfoagronómicas y las evaluativas como respuesta a factores bióticos y abióticos. Estos caracteres se denominan descriptores morfológicos. Los descriptores se seleccionan con base en características cualitativas y cuantitativas, conociendo previamente la variabilidad de los caracteres dentro y entre las plantas (Enríquez, 1991).

Acorde con lo anterior, el objetivo de este trabajo consideró la caracterización y descripción in situ y uso de los frutales nativos de la familia Ericaceae, ya que pueden significar fuentes de mejoramiento de las condiciones socioeconómicas de las comunidades; paralelamente, el cultivo de estas especies puede en el futuro prestar innumerables servicios ambientales como: albergue a la avifauna, valor estético, protección de aguas, de suelos y mejoramiento microclimático.

\section{MATERIALES Y MÉTODOS}

El trabajo se realizó durante el año 2007, en las cuencas altas de los ríos Guamuez y Pasto, del departamento de Nariño, pertenecientes a las cuencas del Amazonas y Pacífica, respectivamente. La zona muestreada se ubicó entre los 2.700 y los $3.100 \mathrm{msnm}$, en las zonas de vida bosque montano bajo (bm-B) y bosque muy húmedo montano (bmh-M). Las unidades muéstrales fueron transectos; el método para situarlas fue preferencial, se basó en el reconocimiento y la información obtenida conjuntamente con la comunidad; los transectos fueron distribuidos en las dos cuencas, procurando abarcar los distintos ecosistemas y agroecosistemas existentes en la región; se trazaron siguiendo los gradientes altitudinales. Para identificar las especies frutales nativas pertenecientes a la familia Ericaceae, se obtuvo información primaria en campo, con la participación activa de la comunidad, especialmente en cuanto a su localización, identificación por su nombre regional y uso. Se hicieron visitas prel iminares de reconocimiento a la zona de estudio y visitas con acompañamiento.

Recolección de muestras botánicas. Con la ayuda de un mapa de la zona y fotografías aéreas se localizaron los bosques primarios, secundarios, plantaciones forestales, huertos caseros, cultivos y áreas de potreros donde hacen presencia las especies frutales de la familia Ericaceae. Para la recolección del material vegetal se establecieron siete rutas de recorrido, en las que se tomo la información respectiva. En cada sitio de evaluación se tomaron tres muestras botánicas por cada ejemplar, una original y dos duplicados, las cuales fueron Ilevadas al herbario de la Universidad de Nariño para su respectiva identificación, registrando en cada uno de ellos los datos de pasaporte.

Usos de las especies. El uso de los frutales nativos en la cuenca al ta de los ríos Guamuez y Pasto se recolectó en 25 encuestas dirigidas a los propietarios de los predios que se encuentran en 
el área de estudio, quienes han heredado los conocimientos tradicionales de sus antepasados.

Caracterización morfológica. En las muestras encontradas en las rutas establecidas se registraron los descriptores morfológicos para la caracterización fenotípica in situ. La información se registró en todos los individuos considerados como pertenecientes a las especies de frutales nativos de la familia Ericaceae.

\section{RESULTADOS Y DISCUSIÓN}

Se describieron un total de 27 muestras de especies frutales silvestres de la familia Ericaceae, las cuales se ubicaron a lo largo de la cuenca alta de los ríos Guamuez y Pasto. Las especies de esta familia reportadas en el presente estudio son arbustos de diferentes tamaños, con al turas que llegan hasta los $5 \mathrm{~m}$. Las muestras estudiadas correspondieron a nueve especies, representadas en seis géneros, identificados como Thibaudia floribunda, Disterigma acuminatum, Gaultheria cordifolia, Gaultheria foliosa, Gaultheria insipida, Cavendishia tubiflora, Cavendishia bracteata, Macleania rupestris, Vaccinium floribundum. La especie más representativa fue Disterigma acuminatum, y la que se encontró en menor porcentaje fue Vaccinium floribundum.

En cuanto a la distribución geográfica de la familia Ericaceae, en las cuencas altas de los ríos Guamuez y Pasto, el $25,93 \%$ de las muestras estudiadas se encontraron en el transecto del Morasurco; el 22,22\%, en el Galeras, y el 3,70\%, en Santa Rosa (tabla 1). Una amplia distribución se presenta en la cuenca alta del río Pasto, con 20 muestras $(74,07 \%)$, localizada entre los 2.521 y $3.327 \mathrm{msnm}$.

Tabla 1. Distribución geográfica de las muestras de especies frutales de la familia Ericaceae, encontradas en las cuencas altas de los ríos Guamuez y Pasto.

\begin{tabular}{|l|c|c|c|c|}
\hline Transecto & Cuenca & Altitud (msnm) & Colectas & Porcentaje \\
\hline Romerillo & Guamuez & $2.824-2.837$ & 3 & 11,11 \\
\hline El Socorro & Guamuez & $2.954-3.043$ & 3 & 11,11 \\
\hline Santa Rosa & Guamuez & 2.877 & 1 & 3,70 \\
\hline Buesaquillo & Pasto & $3.049-3.097$ & 3 & 11,11 \\
\hline Morasurco & Pasto & $2.996-3.267$ & 7 & 25,93 \\
\hline Galeras & Pasto & $3.327-3.341$ & 6 & 22,22 \\
\hline Jamondino & Pasto & $2.521-2.871$ & 4 & 14,81 \\
\hline Total & & & 27 & 100,00 \\
\hline
\end{tabular}

\section{Generalidades de las especies frutales silvestres de la familia Ericaceae}

Cavendishia bracteata Ruiz \& Pav. Conocida vulgarmente con el nombre de asnalulo, es un arbusto terrestre o epífito, de 1 a $4 \mathrm{~m}$ de altura, lianoide, arborescente hasta $5 \mathrm{~m}$ de altura, corteza café a café grisáceo, tallo estriado, glabro (figura 1a).

Las hojas de C. bracteata son oblongas, elípticas - lanceoladas, base redondeada, cordada, cuneada, ápice agudo hasta acuminado, envés liso, nervaduras prominentes desde la base (figura 1b); los peciolos son rugosos y glabros. La

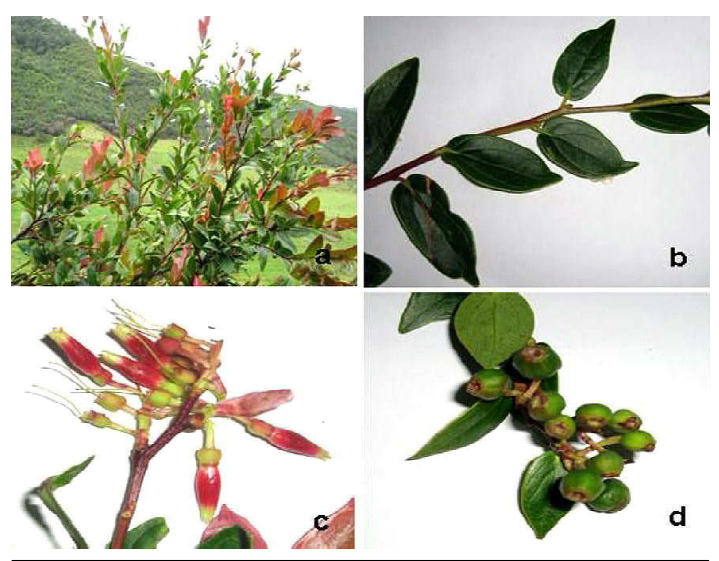

Figura 1. (a) Planta de Cavendishia bracteata, (b) hojas, (c) inflorescencia y (d) frutos. 
inflorescencia presenta las flores encerradas en la base por brácteas, las cuales pueden ser glabras, ápice redondeado o agudo, rosado hasta rojo oscuro, pedicelo a menudo hinchado, verde pálido hasta rojizo, rosado o rojizo oscuro, glabro o piloso. Con respecto a la flor, el cáliz es glabro de 3,5 a 4,6 mm de longitud, de color verde pálido hasta rojo; la corola es cilíndrica o con forma de botella, angosta hasta amplia, glabro, de color rojo, rosado pálido o blanco en la base; las anteras son de color amarillento, blanco o beige (figura 1c). El fruto es una baya glabra o esparcidamente pilosa, de 8 a $14 \mathrm{~mm}$ de diámetro, verde en fresco, morado en maduro y de sabor agradable; cada fruto contiene aproximadamente 96 semillas (figura 1d).

C. bracteata tiene un amplio rango de adaptación; en la zona de estudio se la encontró en varios ecosistemas, con preferencia en los bosques secundarios, orillas de caminos, carreteras y fuentes hídricas. Esta especie se puede encontrar en bosques primarios o en secundarios, en bosques húmedos tropicales, Iluviosos, de niebla, robledales, en el páramo, pantanos, matorrales, colinas rocosas a orillas de carreteras, cañones, orillas de ríos y orillas del bosque en altitudes de 3.000 a 4.090 msnm. La floración y fructificación ocurre a lo largo del año y de manera muy local. Es extremadamente variable en cuanto a su morfología (Romero, 1991).

Macbride (1959) indica que C. bracteata posee frutos de sabor muy agradable que maduran en verde. Las hojas de esta especie contienen tanoides (ácido tánico), lo mismo que los frutos. Se usan en decocción como astringentes y antirreumáticos (García, 1975). Esta especie merece cultivarse para repoblar áreas desnudas de vegetación y defender el medioambiente (Camargo, 1996). C. bracteata es de importancia para campañas de un adecuado aprovechamiento de los páramos de Colombia (Romero, 1991).

Macleania rupestris Kunth A. C. Sm. Recibe diferentes nombres, según la región: en Cundinamarca y Boyacá es conocida vulgarmente con el nombre de uva camarona y uvita, y en Cauca, Putumayo y Nariño se le denomina chaquilulo (Acero y Bernal, 2003). Es un arbusto epífito o terrestre de 0,6 a 2,0 m de altura, de ramificación glabra (figuras 2a y 2b). Las hojas son oblongas, raramente elípticas, con base cuneada a ampliamente redondeada (figura 2c); el ápice es ancho-redondeado hasta agudo, margen subentero, usualmente glabro en ambas caras, pero ocasionalmente corto pubescente; pinadamente venado, nervadura central ligeramente impresa arriba y prominentemente elevada abajo, peciolos rugosos usualmente glabros. Las inflorescencias son axilares y se encuentran en el ápice de las ramas; son racimosas con 4 a 20 flores, glabros. Las flores tienen el limbo del cáliz acampanado, con corola de color rojo profundo o rojo-rosado; el cáliz es de color rojo; las anteras amarillentas y pistilo rojo (figura 2d). El fruto es una baya globosa blanco-azulado oscura.

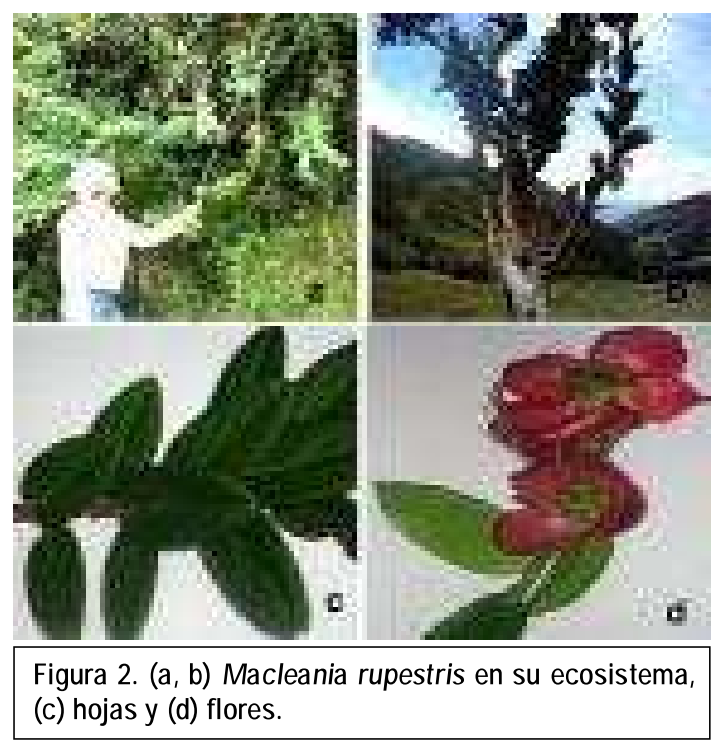

M. rupestris es una especie propia de los páramos y subpáramos; en Colombia se ha coleccionado en los departamentos de Boyacá, Caldas, Cundinamarca, Huila, Magdalena, Meta, Nariño y Norte de Santander, entre los 2.200 y 3.500 msnm; crece en bosques, matorrales, entre pastos y arbustos, en suelos húmedos, pedregosos y arenosos, en áreas abiertas, sobre arbustos y rocas (Pabón, 1981).

Los frutos de $M$. rupestris se utilizan como fruta fresca; son astringentes y se emplean para el control de diarreas crónicas. Las hojas en decocción son utilizadas como antidiarreico y 
en las fiebres tifoideas. Los frutos del chaquilulo se pueden consumir directamente o en forma de jugo o mermeladas. Es interesante también destacar que los pétalos de varias formas de $M$. rupestris son comestibles, con ellos se elaboran dulces en almíbar. Esta especie es utilizada como maderable del bosque montano ecuatoriano por los Saraguros, que es un grupo indígena de la provincia de Loja (Ellemann, 1991).

Rodríguez (1991) realizó el estudio químico de $M$. rupestris; además, elaboró conservas y caramelos a partir de sus frutos, productos sencillos y de muy bajo costo que propuso como alternativa económica para los campesinos.

Vaccinium floribundum Kunth. Conocido como mortiño o, en el comercio, agraz. Es un arbusto pequeño, cuya altura Ilega hasta 2,5 $m$. Con hojas alternas, pequeñas, coriáceas, elípticas a ovado lanceoladas y márgenes finamente aserradas (figura 3a). Las inflorescencias son racimos que salen de las axilas de tallos y hojas, y que tienen de 6 a10 flores pequeñas con cáliz articulado, corola en forma de olla de color blanco, rosa o rojo (figura 3b). El fruto es una baya esférica de 5 a $8 \mathrm{~mm}$ de diámetro de color azul y azul oscuro, lisa a veces glauca (figura $3 \mathrm{c}$ ).

V. floribundum se desarrolla en climas templados y fríos, con temperaturas de 8 a 16 ${ }^{\circ} \mathrm{C}$, y entre 1.600 y $3.800 \mathrm{msnm}$, en los bosques seco montano bajo y húmedo montano, en suelos húmedos y bien drenados (Bernal y Correa, 1990). Su fruto se consume en fresco, como complemento de ensaladas de frutas, vegetales y mezclados con cereales y yogurt; por su sabor fuerte y agradable, se utiliza en la preparación de salsas, acompañamientos para diversos platos de carnes y preparaciones de tipo gourmet, salsas para panqueques, waffles y pastelería variada. En Ecuador se consume fresca o en la tradicional colada morada durante el día de difuntos. En los mercados se presenta como fruta fresca, empacada en bolsas plásticas de una libra y un kilogramo. Se consume en fresco y en algunas ocasiones como jugo natural (Sanjinés et al., 2006).

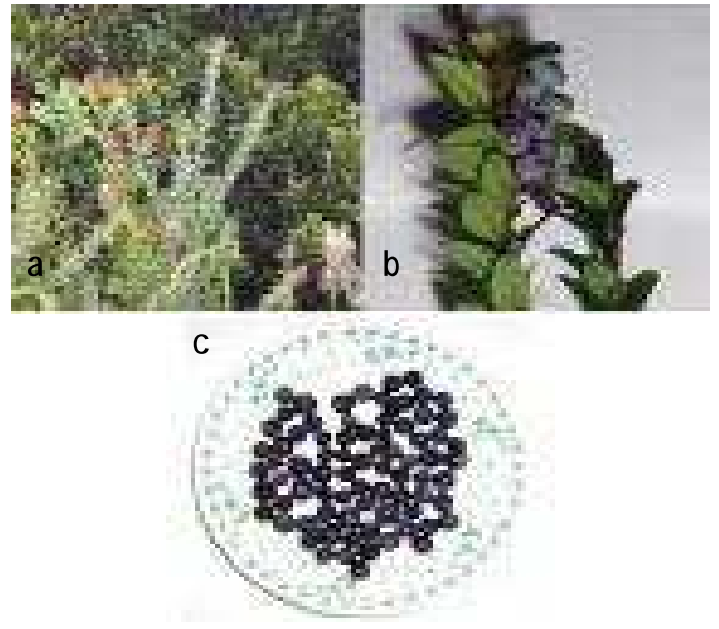

Figura 3. (a) Vaccinium floribundum en su hábitat natural, (b) hoja y (c) frutos.

Thibaudia floribunda Kunth. El género Thibaudia consta de 60 especies distribuidas en Costa Rica, Panamá, la meseta guayanesa y desde Colombia hasta Bolivia (Ulloa y Jorgensen, 2004). Se conoce con el nombre de chaquilulo morado. Es un arbusto de $2 \mathrm{~m}$ de altura. Sus hojas son alternas, coriáceas, lanceoladas, de gran tamaño, con 9 a $13 \mathrm{~cm}$ de largo y de 3 a $4 \mathrm{~cm}$ de ancho, su nerviación es pinnada, la base es redondeada, el ápice atenuado, la margen entera, de superficie glabra y pecíolos cortos (figuras $4 a$ y $4 b$ ). Las inflorescencias se presentan en racimos axilares, fasciculados y terminales, con flores solitarias, de color rojo con blanco y de pedicelos anchos (figura 4b). Los frutos son bayas globosas de 0,5 a 0,8 cm de diámetro, blancos en tiernos, morados en maduros; tienen un delicioso sabor agridulce; se pueden comer en fresco o pueden hacerse almíbares y mermeladas; igualmente, son alimento para una gran variedad de mamíferos y aves.

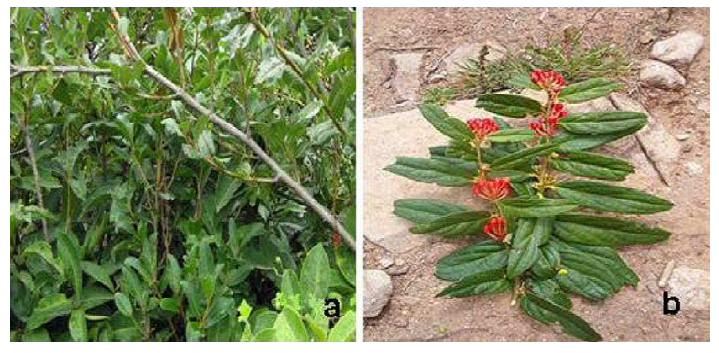

Figura 4. (a) Thibaudia floribunda en asociación con otros arbustos y (b) hojas y flores. 
Cavendishia tubiflora A.C. Smith. Conocida con el nombre vulgar de chaquilulo o quereme. Es un arbusto terrestre o epífito de 2 hasta $4 \mathrm{~m}$ de alto, muy ramificado. Crece a orillas de las carreteras o caminos. Las hojas de $C$. tubiflora son alternas, coriáceas, ovadas, de 6 a $9 \mathrm{~cm}$ de largo, y de 4 a $5 \mathrm{~cm}$ de ancho; la base es aguda, el ápice agudo, margen entera, superficie glabra, pecíolos de 1 a $2 \mathrm{~cm}$ de largo (figura 5a). Las inflorescencias son terminales subtendidas por grandes brácteas laminares de color rojo con flores tubulares de 2,5 a $3 \mathrm{~cm}$ de largo, $0,5 \mathrm{~cm}$ de ancho, rojo oscuras con el extremo blanco. Los frutos son bayas globosas de $1 \mathrm{~cm}$ de diámetro, de color verde negruzco.

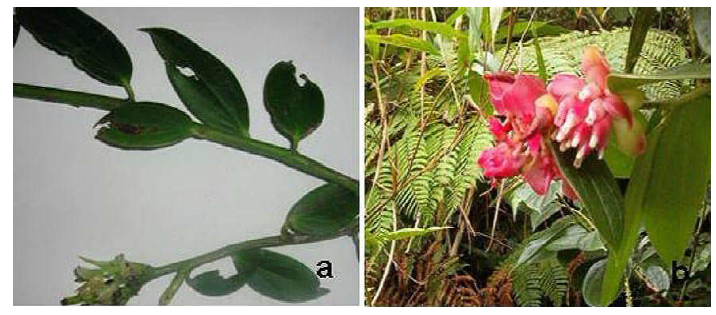

Figura 5. (a) Hojas de Cavendishia tubiflora y (b) flores e inflorescências.
C. tubiflora es otra de las frutas que pueden ayudar a hacer productivos los suelos ubicados en altitudes mayores de $2.400 \mathrm{msnm}$, en las cuales se da espontáneamente; está provista de unas hojas enteras, duras y brillantes que le dan el carácter ornamental que se realza con la aparición de la inflorescencia en racimos, lo que destaca su potencial para programas de ornamentación. Las personas de la zona consumen esta fruta en fresco, en mermeladas, jugos y vinos. Además, es muy visitada por aves como colibríes.

Disterigma acuminatumn, H.B.K. Su nombre vulgar es piqui siqui. Es un arbusto ramoso que mide de $0,5 \mathrm{~cm}$ a $2 \mathrm{~m}$ de alto. Es rastrero, erguido o algo deprimido con ramas duras. Su tallo es pubescente cuando es joven. Crece al lado de caminos, haciendo simbiosis con otras plantas (figura 6a). Las hojas son alternas, elípticas, de 1,3 a $1,9 \mathrm{~cm}$ de largo y de 0,7 a 1,1 cm de ancho, con la base subredondeada, ápice agudo, borde entero, haz glabro, envés espaciadamente piloso, color verde claro (figura 6b). Las flores de color blanco, son solitarias, axilares, en las ramas
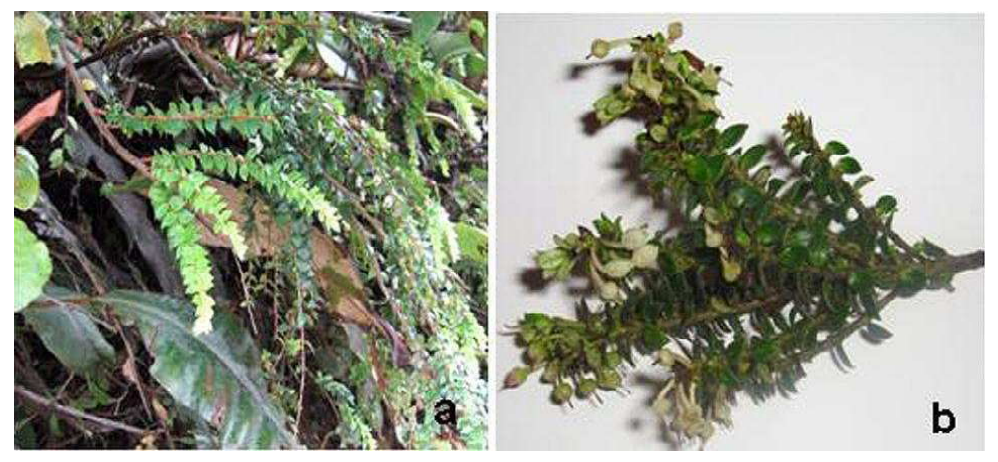

Figura 6. (a) Disterigma acuminatum, (b) flores y hojas.
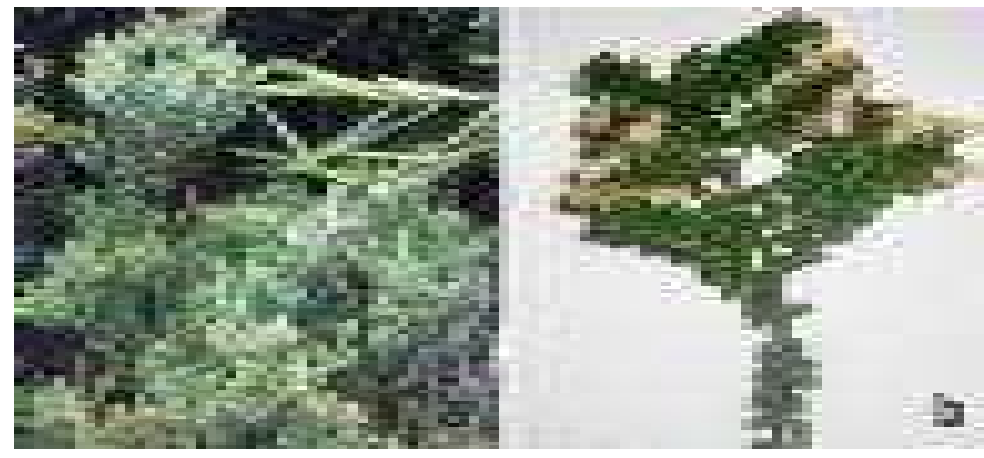

Figura 7. (a) Gaultheria foliosa in situ, (b) hojas y frutos. 
terminales, urceoladas, de $0,6 \mathrm{~cm}$ de largo. Los frutos son bayas globosas, blanco amarillentos, de sabor agridulce; son alimento de aves, y con ellos se puede hacer mermeladas para consumo humano.

Gaultheria foliosa, Benth. Conocida con el nombre vulgar de mote. Es un arbusto o arbolito muy ramificado, variable en tamaño: mide entre 0,5 y 2 m de altura, según las condiciones del suelo (figura 7a). Las hojas son alternas y miden de 1 a $1,5 \mathrm{~cm}$ de largo y de 0,5 a $1 \mathrm{~cm}$ de ancho; son coriáceas, de forma ovada, ápice agudo, base cuneada, borde aserrado; usualmente glabro en ambas caras de color verde oscuro (figura 7b). Las flores están agrupadas en la parte terminal de las ramas en inflorescencias que tienen de 5 a 10 flores pequeñas; su corola es de color rosado pálido. El fruto es una baya esférica de 5 a $8 \mathrm{~mm}$ de diámetro, achatado, de color blanco, de sabor agridulce; sirve de alimento para aves y algunos mamíferos.

Gualtheria cordifolia Kunt. Conocida con el nombre vulgar de pata de gallo. Es un arbusto o arbolito muy variable en tamaño, desde 0,5 hasta $2 \mathrm{~m}$ de altura, de corteza parduzca que se descascara y pubescencia blanca (figura 8a). Las

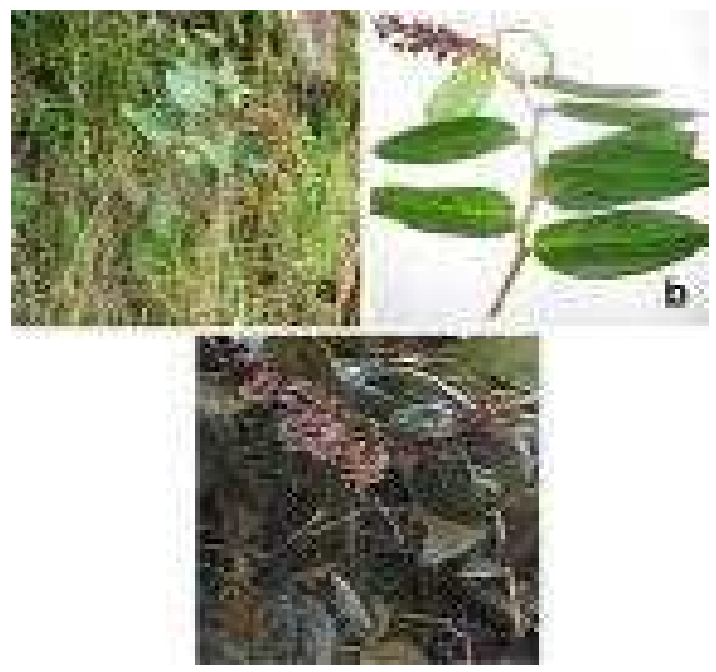

Figura 8. (a) Gaultheria cordifolia en su ambiente, (b) hojas y (c) inflorescencias. hojas son ovaladas, alternas, con ápice agudo, borde entero (figura 8b) y con presencia de pubescencia en hojas y tallo; el pecíolo presenta una coloración rojiza. Las flores presentan un cáliz de color morado, en inflorescencias con racimo de color rosado (figura 8c). El fruto, dispuesto en forma de infrutescencia, es una baya esférica de color negruzco se puede consumir directamente en fresco; también es alimento de algunos mamíferos y aves.

Gaultheria insípida Benth. Su nombre vulgar es pata de gallina. Es un arbusto pequeño hasta mediano, con ramas glabras, algunas veces setosas. Tallo de color rojizo que alcanza los 1,5 $\mathrm{m}$ de altura (figura 9a). Las hojas van desde ovalada hasta redondeada, se encuentran dispuestas en forma alterna, con ápice acuminado, borde aserrado, pubescente; el pecíolo presenta una coloración rojiza (figura 9b). Las flores tienen una corola de color blanco traslúcido a rosado, dispuestas en inflorescencias racimosas de color rojizo (figura 9c). El fruto se presenta en infrutescencias con bayas esféricas de color morado en estado maduro, las cuales son alimento para aves y algunos mamíferos; también puede ser consumido por el hombre por su sabor agridulce.

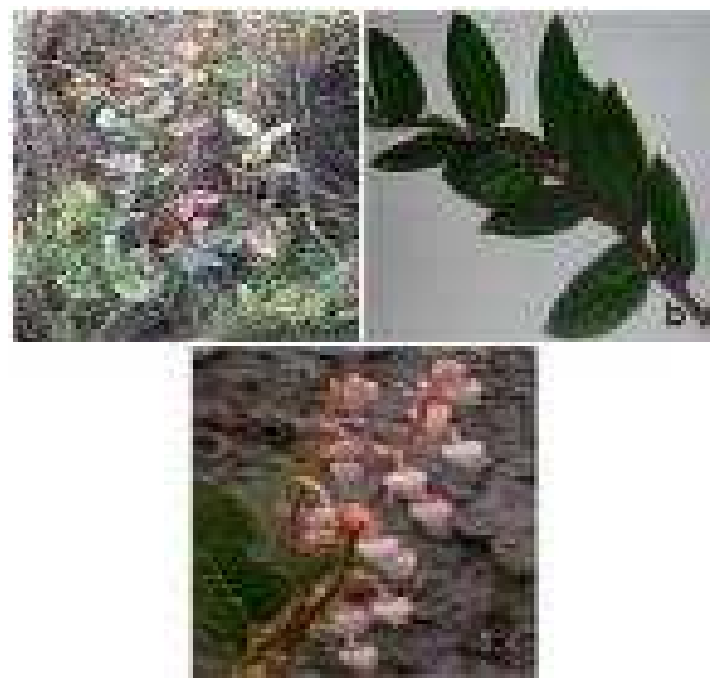

Figura 9. (a) Gaultheria insípida en su ambiente, (b) hojas y (c) inflorescencias. 


\section{CONCLUSIONES}

Se encontraron nueve especies de frutales nativos no cultivados y de uso común que corresponden a siete géneros de la familia Ericaceae, en un rango altitudinal entre los 2.700 y los 3.100 msnm. El mayor número de especies de la familia Ericaceae se reporta en la cuenca alta del Río Pasto, con respecto a la cuenca alta del río Guamuez.

Los habitantes de la zona tienen escaso conocimiento sobre el manejo de estas especies. Su consumo es restringido. Una pequeña parte se utiliza para preparar dulces y mermeladas. Los frutos de las especies Vaccinium floribundum y Macleania rupestris se cosechan y comercializan en galerías y supermercados de la ciudad de Pasto y municipios aledaños.

Estas especies frutales crecen como producto de la sucesión natural, especialmente en áreas que no han sufrido el cambio de uso del suelo; tienen un alto valor ecológico en la protección de ecosistemas frágiles, como las zonas de recarga hídrica, y, además, se pueden utilizar en programas de restauración ecológica por su alta capacidad de adaptación a condiciones adversas climáticas y de suelos.

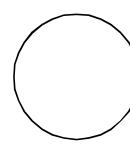

Acero, L.E. y H.Y. Bernal. 2003. El cultivo, aprovechamiento y conservación de la uva camarona Macleania rupestris (H.B.K) AC, Smith. Convenio Andrés Bello, Bogotá

Bernal, H. y J. Correa. 1990. Especies vegetales promisorias de los países del Convenio Andrés Bello. Tomo VII. SECAD, Bogotá

Camargo, L.A. 1996. Cavendishia bracteata. Catálogo ilustrado de las plantas de Cundinamarca. Imprenta Nacional, Bogotá

Ellemann, L. 1991. El uso de la madera del bosque montano por los Saraguros. Interamericana, Quito.

Enríquez, G.A. 1991. Descripción y evaluación de los recursos genéticos. En: INIAP. Técnicas para el manejo y uso de recursos genéticos vegetales. Instituto Nacional de Investigaciones Agropecuarias, Departamento de Recursos Genéticos, Quito.

García, H. 1975. Cavendshia bracteata. En: Flora medicinal de Colombia. Imprenta Nacional, Bogotá

Hidalgo, R. 2003. Variabilidad genética y caracterización de especies vegetales. Boletín Técnico Instituto Internacional de Recursos Fitogenéticos. IPGRI,

\section{REFERENCIAS BIBLIOGRÁFICAS}

Cali, Colombia.

Kron, K.A.; E.A. Powell y J.L. Luteyn. 2002. Phylogenetic relationships within the blueberry tribe (Vaccinieae, Ericaceae) based on sequence data from matK and nuclear ribosomal ITS regions, with comments on the placement of Satyria. Amer. J. Bot. 89, 327-336

Ligarreto, G.A.; M. Lobo y A. Correa. 2005. Recursos genéticos del género Physalis en Colombia. pp. 927. En: Fischer, G.; D. Miranda; W. Piedrahita y J. Romero (eds.). Avances en cultivo, poscosecha y exportación de la uchuva (Physalis peruviana L.) en Colombia. Unibiblos, Universidad Nacional de Colombia, Bogotá.

Luteyn, J. 2002. Diversity, adaptation and endemism in Neotropical Ericaceae: Biogeographical patterns in the Vaccinieae. Bot. Rev. 68(1), 55-87.

Luteyn J.L. y P. Pedraza-Peñalosa. 2008. Neotropical blueberries: The plant family Ericaceae. The New York Botanical Garden. www.nybg.org/bsci/res/ lut2/; consulta: 12 de mayo de 2008.

Luteyn, J.L. y D.S. Sylva. 1999. "Murrí» (Antioquia Department, Colombia): Hotspot for neotropical blueberries (Ericaceae: Vaccinieae). Brittonia 51, 280-302. 
Macbride, F.J. 1959. Cavendishia bracteata. En: Flora of Peru. Field Mus. Nat. Hist. Bot.

Maecha, G. 1997. Fundamento y metodología para la identificación de plantas. Proyecto Biopacífico. Ministerio del Medio Ambiente, Bogotá

National Research Council. 1989. Lost crops of the Incas. National Academy Press, Washington.

Pabón, M.A. 1981. Flora genérica de Colombia. Familia Ericaceae. Trabajo de grado. Facultad de Ciencias, Universidad Nacional de Colombia, Bogotá.

Pennington, J. y R. Fisher. 2009. Classification of fruits and vegetables. J. Food Compos. Anal. 30(3), 1-9.

Rodríguez, J. 1991. Contribución al estudio químico de Macleania rupestris y preparación de mermeladas con sus frutos. Pontificia Universidad Javeriana, Bogotá

Romero, R. 1991. Frutas silvestre de Colombia. 2a. edición. Editorial ABC, Bogotá.

Salinas, N. R. y J. Betancur. 2005. Las ericáceas de la vertiente pacífica de Nariño, Colombia. Instituto de Ciencias Naturales e Instituto de Investigación de Recursos Biológicos Alexander von Humboldt, Bogotá.

Sanjinés, A.; B. Asturizaga y B. Henrik. 2006. Frutos comestibles, botánica económica de los Andes Centrales. Universidad Mayor de San Andrés, La Paz. pp. 329-346

Smith, N.; S.A. Mori; A. Henderson; D.W. Stevenson y S.V. Heald. 2004. Flowering plants of the Neotropics. Princeton University Press, Princeton, NJ

Ulloa, C. y P.M. Jorgensen. 2004. Árboles y arbustos de los Andes del Ecuador. En: http://www. efloras.org/ flora_page.aspx?flora_id=201; consulta: noviembre de 2009

Vásquez, R. y G. Coímbra. 2002. Frutas silvestres comestibles de Santa Cruz. 2a. edición. Fundación Amigos de la Naturaleza, Santa Cruz, Bolivia.

Vavilov, N.I. 1960. Estudio sobre el origen de las plantas cultivadas. Ediciones ACME Agency S.R., Buenos Aires. 